\title{
Influence of Deposition Parameters on the Properties of CdTe Films Deposited by Close Spaced Sublimation
}

\author{
Vivienne Denise Falcão*, Wagner Anacleto Pinheiro, Carlos Luiz Ferreira, Leila Rosa de Oliveira Cruz. \\ Instituto Militar de Engenharia, \\ Departamento de Engenharia Mecânica e de Materiais, Laboratório de Filmes Finos, \\ Praça General Tibúrcio, 80, Urca, 22290-270 Rio de Janeiro - RJ, Brazil
}

Received: December 2, 2004; Revised: July 13, 2005

\begin{abstract}
CdTe thin films are used as absorber layer in CdS/CdTe solar cells. The microstructure of this absorber layer plays a fundamental role in photovoltaic conversion and can be controlled by the deposition parameters used during the film growth. In this work, CdTe thin films were deposited by the CSS method onto glass substrates previously covered with $\operatorname{In}_{2} \mathrm{O}_{3}: \mathrm{Sn}$. The effects of pressure, source temperature and substrate temperature on the microstructural properties of the films were studied. The properties were mainly influenced by the pressure, the presence of oxygen in the reaction chamber, and the substrate temperature. For films deposited under an argon atmosphere, an increase in grain size and a reduction of the texture were observed as the pressure and substrate temperature were increased. The introduction of oxygen in the atmosphere led to a decrease in the deposition rate and affected the microstructure and composition of the film. Films deposited under an argon-oxygen atmosphere have smaller grains than those deposited under argon and are richer in Te. The addition of oxygen to the atmosphere apparently did not result in the formation of oxides.
\end{abstract}

Keywords: CdTe, CSS, deposition parameters

\section{Introduction}

Cadmium telluride (CdTe), because of its ideal bandgap (1.5 eV) and its high absorption coefficient $\left(>10^{4} \mathrm{~cm}^{-1}\right)$, has been recognized as a very promising material for low cost and high efficiency thin film solar cells, such as CdS/CdTe. Besides, CdTe it is a stable compound and it can be deposited by several techniques including electrodeposition, screen printing, and close spaced sublimation (CSS). All these techniques are able to produce polycrystalline CdTe thin films. However, the highest efficiency solar cell ${ }^{1}-16.5 \%$ - has been prepared by CSS. This technique is characterized by the short distance between the source and the substrate and it is particularly attractive for depositing CdTe films since it offers high depositions rates, it is able to produce films with larger grains than those deposited by other techniques and can be easily scaled up for manufacturing purposes. Moreover, it does not require any elaborate equipment because the pressures required are in the low vacuum range and the temperatures used are $750{ }^{\circ} \mathrm{C}$ at most.

The microstructure of CdTe absorber layer plays a fundamental role in the photovoltaic conversion and can be controlled by the deposition parameters used during the film growth. In CSS technique, the source and substrate temperatures, the system pressure and the oxygen partial pressure are the most important deposition parameters, deeply affecting the physical and microstructural properties of the film. Several works have been published about the effect of these parameters ${ }^{2-4}$. For example, some authors ${ }^{5}$ report that a small amount of oxygen during the growth of the film plays a very important role in the layer of CdTe, contributing for increasing p-type conductivity and decreasing resistivity. However, grain size is reduced. In spite of these several works, the impact of oxygen incorporation on the process of film growth is still not well understood. In the present work, the effects of pressure, source temperature and substrate temperature, as well as the effect of oxygen incorporation on the microstructural properties of the CdTe films deposited by CSS were studied. In addition, this work also shows the influence of these parameters in the deposition rate.

\section{Experimental}

The CdTe films were deposited on glass substrates previously covered with $\mathrm{In}_{2} \mathrm{O}_{3}: \mathrm{Sn}$ (ITO) in homemade CSS equipment ${ }^{6}$. Details of the deposition process can be seen in the literature ${ }^{7}$. Basically, the CSS technique involves the sublimation of a CdTe source which is separated from the substrate for a distance of millimeters. The CdTe source used in this work was a paste made of CdTe and propylene glycol. This paste was applied directly on a graphite block and dried at $200{ }^{\circ} \mathrm{C}$ for 1 hour. The source and substrate temperatures, $\mathrm{T}_{\text {so }}$ and $\mathrm{T}_{\text {sub }}$, ranged from 650 to $750{ }^{\circ} \mathrm{C}$ and 500 to $650{ }^{\circ} \mathrm{C}$, respectively. The source-substrate distance was $2.7 \mathrm{~mm}$. The pressure of the system was varied between 0.1 and 20 Torr using pure argon $\left(\mathrm{P}_{\mathrm{Ar}}\right)$ or a mixture of argon-oxygen $\left(\mathrm{P}_{\text {mix }}\right)$. The mixture composition was varied between 0 and $100 \%$ of oxygen. The films were 1-3.5 $\mu \mathrm{m}$ thick. The thickness was measured using a Veeco Dektak 3 profiler. $\mathrm{X}$ ray diffraction (XRD) analyses were carried out in Philips and Siemens diffractometers, model PW1710 and D5000, respectively. The morphology and composition of the films were evaluated in a JEOL JSM 5800LV Scanning Electron Microscope (SEM) equipped with an energy dispersive spectroscopy (EDS) accessory, from NORAN 688A-1SSS. The grain size was measured by the intercept method $^{8}$. 


\section{Results and Discussion}

\subsection{Influence of deposition parameters on the deposition rate}

Table 1 shows the effect of the source and substrate temperatures on the deposition rate of CdTe films deposited under an argon pressure of 10 Torr. The deposition rates were calculated from the ratio between the thickness and the deposition time. It can be observed that the deposition rate increases as the source temperature increases and as the substrate temperature decreases. This behavior is in accordance with the diffusion limited rate model ${ }^{7}$. However, the values of the deposition rate were lower than those predicted by the model, probably due to the low adhesion coefficient of the CdTe on the substrate. This model assumes a value of 1 for the adhesion coefficient, which means that all the atoms arriving to the substrate will adhere to it. So, the lower deposition rate values suggest that the adhesion coefficient is lower than 1. This would affect the nucleation and the growth of the first monolayer, leading to an increase of the deposition time.

Table 2 shows the effect of the argon pressure on the deposition rate of CdTe films deposited on substrates kept at $600{ }^{\circ} \mathrm{C}$ and from a source kept at $750{ }^{\circ} \mathrm{C}$. The deposition rate increases as pressure decreases down to 1 Torr. This behavior is also predicted by the diffusion limited rate $\operatorname{model}^{7}$. Again, the experimental values of the deposition rate were smaller than theoretical values, due the poor adhesion of CdTe film onto the substrate. Further pressure reductions don't affect the rate because at low pressures the rate is limited by free evaporation, a pressure-independent process.

Table 3 shows the effect of the oxygen addition to gaseous atmosphere on the deposition rate of $\mathrm{CdTe}$ films grown onto substrates kept at $600{ }^{\circ} \mathrm{C}$, from a source kept at $750{ }^{\circ} \mathrm{C}$, and under a total pressure of 10 Torr. Addition of less than $10 \%$ oxygen to the argon atmosphere didn't cause any important change in the deposition rate. Above $10 \%$ the deposition rate decreases, the reduction being very steep for those films deposited in presence of pure oxygen. These results agree pretty well with the literature ${ }^{2,5}$. The deposition rate decrease is probably due to the reaction between tellurium and/or cadmium molecules and oxygen molecules, during their transport to the substrate. In principle, this reaction could favor oxides formation. The role of the oxygen on the properties of CdTe films has been widely investigated ${ }^{2,5}$. It is known that the presence of oxygen in the films improves the cell efficiency. However, the mechanisms involved in this process are not well understood at this time.

\subsection{Influence of deposition parameters on the microstructure}

Table 4 shows the grain size of CdTe films deposited from a source kept at $750{ }^{\circ} \mathrm{C}$, under 10 Torr of argon, at different substrate temperatures. In order to isolate the effect of the film thickness in this analysis, films of same thickness had been selected $(3.0 \mu \mathrm{m})$. It is observed that the increase of the substrate temperature led to an increase in the grain size. This increase, that has also been observed in the literature ${ }^{3,9,10}$, is due to the low deposition rate achieved at higher substrate temperatures, as shown in Table 1, and also to the higher mobility of atoms on substrates heated at higher temperatures.

While substrate temperature caused important changes on grain size of the films, source temperature did not affect it significantly. This indicates that the dominant mechanism governing grain growth in these films is the substrate temperature, which contributes to enhance the diffusion of atoms on substrate surface.

The influence of the argon pressure on the grain size of CdTe films deposited at substrate and source temperatures of $600{ }^{\circ} \mathrm{C}$ and $750{ }^{\circ} \mathrm{C}$, respectively, is shown in Table 5 . In order to isolate the ef-
Table 1. Deposition rate of CdTe films deposited under $\mathrm{P}_{\mathrm{Ar}}=10$ Torr at different source and substrate temperatures.

\begin{tabular}{ccc}
\hline $\mathrm{T}_{\text {sub }}\left({ }^{\circ} \mathrm{C}\right)$ & \multicolumn{2}{c}{ Deposition rate $(\mu \mathrm{m} / \mathrm{min})$} \\
& $\mathrm{T}_{\text {so }}=700{ }^{\circ} \mathrm{C}$ & $\mathrm{T}_{\text {so }}=750{ }^{\circ} \mathrm{C}$ \\
\hline 530 & 0.07 & - \\
570 & 0.07 & 0.21 \\
600 & 0.02 & 0.20 \\
650 & - & 0.17 \\
\hline
\end{tabular}

Table 2. Deposition rate of CdTe films deposited at $\mathrm{T}_{\mathrm{so}}=750^{\circ} \mathrm{C}, \mathrm{T}_{\text {sub }}=600^{\circ} \mathrm{C}$, under different argon pressures.

\begin{tabular}{lllll}
\hline $\mathrm{P}_{\mathrm{Ar}}($ Torr $)$ & 0.1 & 1.0 & 10 & 20 \\
\hline Deposition rate $(\mu \mathrm{m} / \mathrm{min})$ & 0.60 & 0.60 & 0.20 & 0.12 \\
\hline
\end{tabular}

Table 3. Deposition rate of CdTe films deposited at $\mathrm{T}_{\mathrm{so}}=750{ }^{\circ} \mathrm{C}, \mathrm{T}_{\mathrm{sub}}=600^{\circ} \mathrm{C}$, $\mathrm{P}_{\text {mix }}=10$ Torr, using different amounts of oxygen in the gaseous atmosphere.

\begin{tabular}{llllr}
\hline$\% \mathrm{O}_{2}$ & 0.0 & 10 & 20 & 100 \\
\hline Deposition rate $(\mu \mathrm{m} / \mathrm{min})$ & 0.20 & 0.19 & 0.15 & 0.08 \\
\hline
\end{tabular}

Table 4. Grain size of CdTe films deposited at $\mathrm{T}_{\mathrm{so}}=750{ }^{\circ} \mathrm{C}, \mathrm{P}_{\mathrm{Ar}}=10$ Torr, at different substrate temperatures.

\begin{tabular}{lccc}
\hline $\mathrm{T}_{\text {sub }}\left({ }^{\circ} \mathrm{C}\right)$ & 570 & 600 & 650 \\
\hline Grain size $(\mu \mathrm{m})$ & 1.85 & 2.05 & 2.53 \\
\hline
\end{tabular}

Table 5. Grain size of CdTe films deposited at $\mathrm{T}_{\mathrm{so}}=750{ }^{\circ} \mathrm{C}, \mathrm{T}_{\text {sub }}=600{ }^{\circ} \mathrm{C}$ under different argon pressures.

\begin{tabular}{llllc}
\hline $\mathrm{P}_{\mathrm{Ar}}($ Torr $)$ & 0.1 & 1.0 & 10 & 20 \\
\hline Grain Size $(\mu \mathrm{m})$ & 0.92 & 1.20 & 1.64 & 1.55 \\
\hline
\end{tabular}

fect of the film thickness in this analysis, films of same thickness had been selected $(1.9 \mu \mathrm{m})$.

For argon pressures up to 10 Torr, the average grain size increases with the pressure, remaining almost unchanged for pressures above this value. This behavior can be understood in view of the results shown in Table 2, which showed that the deposition rate decreased as the pressure increased, thus favoring the grain growth. For pressures above 10 Torr, despite the decrease of the deposition rate, the grain size remains almost constant. This suggests that a competitive mechanism is limiting grain growth. One explanation is that, in such a high range of pressure, the number of collisions between $\mathrm{Te}$ and $\mathrm{Cd}$ atoms in the vapor phase and argon molecules is very high. Thus, the kinetic energy of $\mathrm{Cd}$ atoms is critically reduced, not contributing for further grain growth. It is important to point out that some authors ${ }^{9}$ observed even an important decrease in grain size of these films deposited at the same range of pressures.

Figure 1 shows the XRD spectra of CdTe films deposited under 10 Torr, from a source kept at $750{ }^{\circ} \mathrm{C}$, at different substrate temperatures. All the films are crystalline. The ITO diffracted peaks come from the substrate. Those films deposited at lower temperatures has a [220] preferred orientation. As the temperature increases, the 


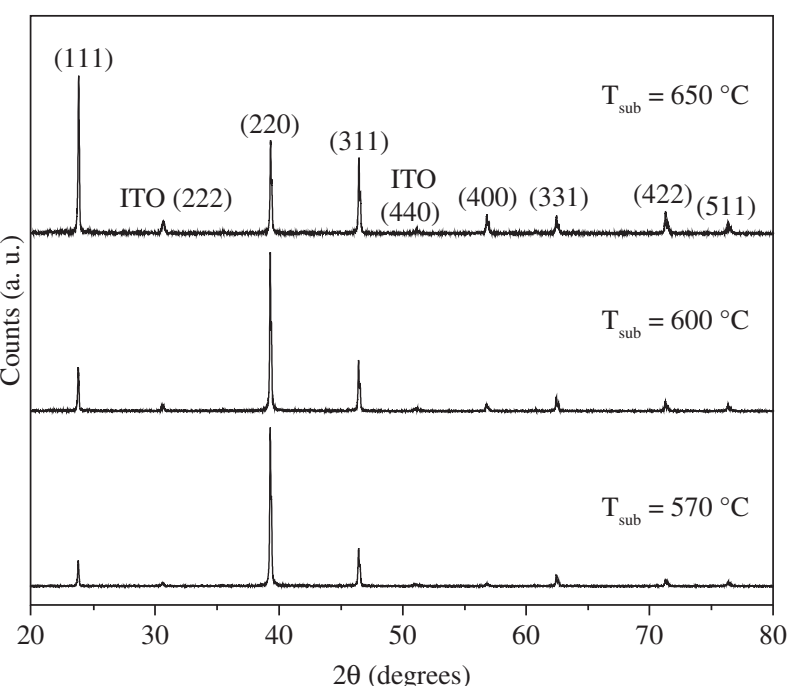

Figure 1. XRD spectra of CdTe films deposited at different substrate temperatures, with $\mathrm{T}_{\mathrm{so}}=750{ }^{\circ} \mathrm{C}$ and $\mathrm{P}_{\mathrm{Ar}}=10$ Torr.

oriented growth changes to random growth. This can be explained considering that at higher temperatures the entropy is higher, thus favoring the random growth ${ }^{11}$.

The previous results show that, even though there is an increase of the grain size when the substrate temperature increases, there is a loss of preferential growth. Thus, in order to make high efficiency solar cells, these two characteristics should be taken into account.

Figure 2 shows the surface morphology of CdTe films deposited at source and substrate temperatures of $750{ }^{\circ} \mathrm{C}$ and $600^{\circ} \mathrm{C}$, respectively, under a total pressure of 10 Torr, and the gaseous mixture composed of: a) $0 \%$ of $\mathrm{O}_{2}\left(10 \mathrm{Torr}\right.$ of $\mathrm{Ar}$ ); and (b) $10 \%$ of $\mathrm{O}_{2}\left(1\right.$ Torr of $\mathrm{O}_{2}$ and 9 Torr of Ar). It can be seen that the presence of $\mathrm{O}_{2}$ in the chamber led to a reduction of the grain size. This decrease was also observed for higher additions of $\mathrm{O}_{2}$. Thus, in spite of decreasing deposition rate (see Table 3 ), the introduction of oxygen did not contribute to an increase of the grain size. On the contrary, oxygen additions in the chamber led to a reduction in grain size. Such result has also been observed by Ferekides et al. ${ }^{3}$ and Romeo et al. ${ }^{4}$. These authors suggest that oxygen affects the nucleation process, increasing the number of nucleation sites.

The XRD spectra of CdTe films deposited at source and substrate temperatures of $750{ }^{\circ} \mathrm{C}$ and $600{ }^{\circ} \mathrm{C}$, respectively, under total pressure of 10 Torr, using different percentages of oxygen are shown in Figure 3 . The spectra were obtained in the grazing incidence mode. This is the reason for the crescent background at low angles. It can be verified that there are no oxide phases, at least in the crystalline state. It should also be observed that the film showing the highest degree of orientation was the one deposited in an ambient composed of $10 \%$ $\mathrm{O}$. This would result in films with higher carrier mobility, compared to a film deposited in the presence of higher amounts of oxygen.

\subsection{Influence of deposition parameters on composition}

The compositions of the CdTe films deposited at source and substrate temperatures of $750{ }^{\circ} \mathrm{C}$ and $600{ }^{\circ} \mathrm{C}$, respectively, under total pressure of the 10 Torr, and using different amounts of oxygen in the gaseous atmosphere are shown in Table 6.

Although EDS analysis is semiquantitative, a compositional change can be clearly seen in the analyzed films. Films deposited in the presence of oxygen are cadmium deficient, the deficiency

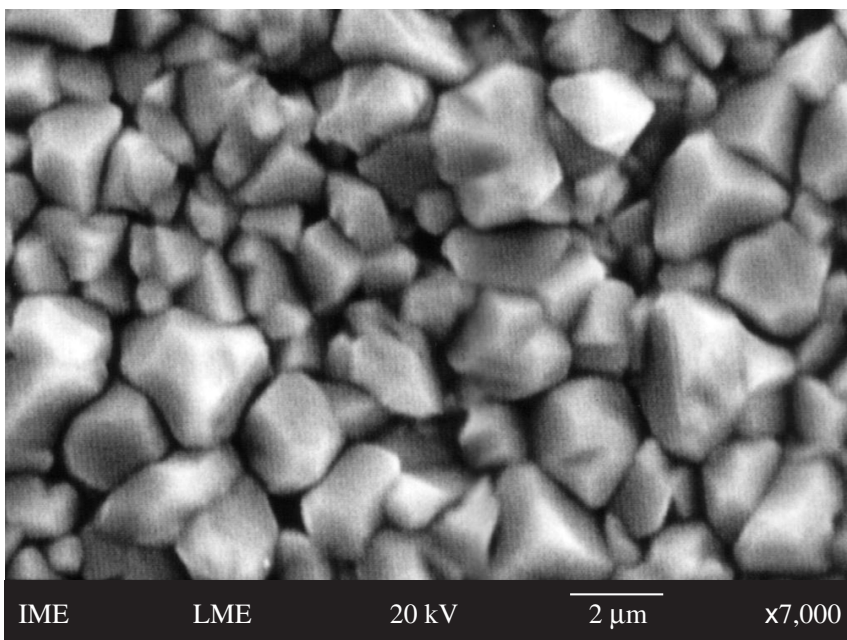

(a)

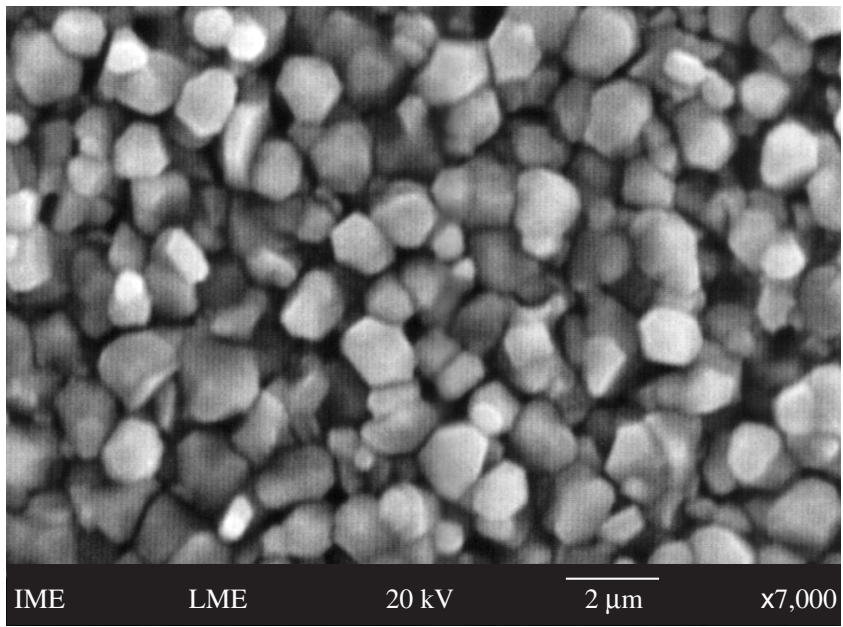

(b)

Figure 2. SEM images of CdTe films deposited at $\mathrm{T}_{\mathrm{so}}=750^{\circ} \mathrm{C}, \mathrm{T}_{\mathrm{sub}}=600{ }^{\circ} \mathrm{C}$ and $\mathrm{P}_{\text {mix }}=10$ Torr: a) $0 \% \mathrm{O}_{2}$; and b) $10 \% \mathrm{O}_{2}$.

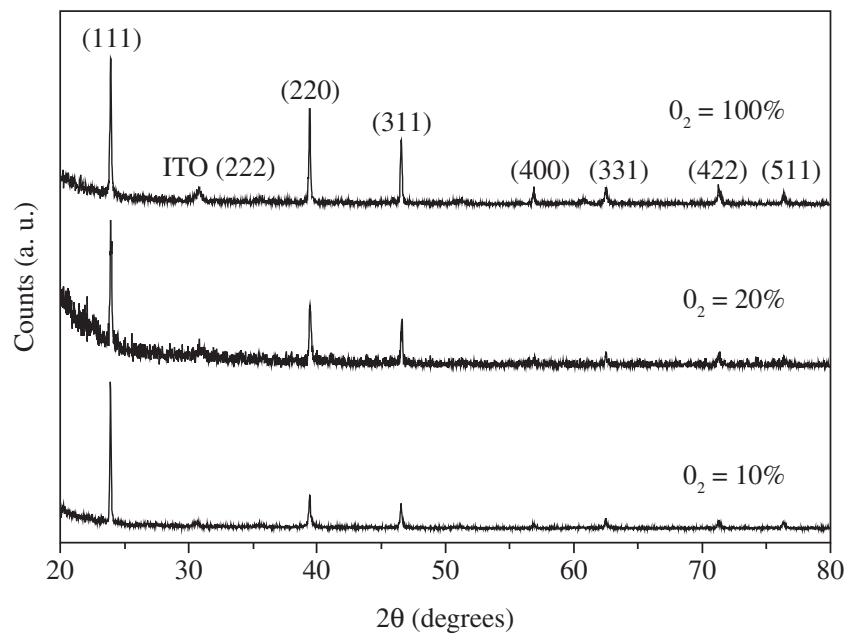

Figure 3. XRD spectra of CdTe films deposited at $\mathrm{T}_{\mathrm{so}}=750{ }^{\circ} \mathrm{C}, \mathrm{T}_{\mathrm{sub}}=600^{\circ} \mathrm{C}$, $\mathrm{P}_{\text {mixt }}=10$ Torr, using different amounts of oxygen in the gaseous atmosphere. 
Table 6. Composition of CdTe films deposited at $\mathrm{T}_{\mathrm{so}}=750{ }^{\circ} \mathrm{C}, \mathrm{T}_{\text {sub }}=600^{\circ} \mathrm{C}$, $\mathrm{P}_{\text {mixt }}=10$ Torr, using different amounts of oxygen in the gaseous atmosphere.

\begin{tabular}{rcc}
\hline$\% \mathrm{O}_{2}$ & $\mathrm{Cd}(\%$ at. $)$ & $\mathrm{Te}(\%$ at. $)$ \\
\hline 0 & 48.34 & 51.66 \\
10 & 46.71 & 53.29 \\
20 & 44.20 & 55.80 \\
\hline
\end{tabular}

increasing with the amount of oxygen. This means that oxygen contributes to form tellurium rich films, a result that is particularly important in order to enhance the p-type character of the films. The role of the oxygen on physical and microstructural properties of CdTe films requires additional investigation. However, the results of this work allow to conclude that addition of oxygen in the chamber favors the generation of cadmium vacancies, probably due the cadmium oxide formation, that does not appear in the XRD spectra probably because it is amorphous or it is present in a small amount. This would explain the decrease of the deposition rate, that is, due to the preferential reaction between oxygen and cadmium, CdTe deposition rate was reduced. As for grain size decreasing, observed in Figure 2, it is possible that the formation of these oxides acts as small nucleation sites, making the grain growth difficult. Additional analyses are being carried out in order to confirm this hypothesis.

\section{Conclusions}

In this work, the effects of pressure, source and substrate temperatures, as well as the effect of the presence of oxygen in the reaction chamber on the microstructural properties of the CdTe films deposited by CSS were studied. The source temperature didn't affect the grain size. On the other hand, the increase of the substrate temperature led to an increase of grain size and a loss of texture in the films. The films deposited at substrates kept at $650{ }^{\circ} \mathrm{C}$, under argon pressure of 10 Torr and from a source kept at $750{ }^{\circ} \mathrm{C}$ had the largest grains $(2.5 \mu \mathrm{m})$.

It was found that presence of oxygen in the chamber led to a decrease in both the deposition rate and grain size of CdTe films. The addition of oxygen also favored the growth of films oriented in the (111) direction. These films are richer in Te than films deposited at the same conditions under a pressure of pure argon, which it is particularly important to enhance the p-type conductivity of CdTe films.

\section{Acknowledgments}

The authors wish to thank Prof. R. Prioli, from Pontifícia Universidade Católica do Rio de Janeiro (PUC-RJ), for thickness measurements and Drs. H.R. Moutinho and R.G. Dhere, from National Renewable Energy Laboratory (NREL-USA), for the suggestions during the deposition of the films. Additional thanks are given to Departamento de Ciência dos Materiais e Metalurgia (DCMM/PUC-RJ) and Centro de Pesquisas da Petrobras (CENPES/PETROBRAS) for X ray spectra. This work was financed by CENPES/PETROBRAS.

\section{References}

1. Wu X, Dhere R, Albin D, Gessert T, Dehart C, Keane J et al. High-efficiency CTO/ZTO/CdS/CdTe polycrystalline thin-film solar cells. NREL/ CP-520-31025. 2001 [cited 2004 Jul 15]; 3. Available from: http:Ilwww. osti.gov/bridge.

2. Contreras-Puente G, Vigil-Galán O, Vidal-Larramendi J, Cruz-Gandarilla F, Hesiquio-Garduño M, Aguilar-Hernández J, Cruz-Orea A. Influence of the growth conditions in the properties of the CdTe thin films deposited by CSVT. Thin Solid Films. 2001; 387:50-53.

3. Ferekides C, Viswanathan V, Tetati B, Palekis V, Selvaraj P, Morel D. CdTe solar cells with efficiencies over 15\%. Thin Solid Films. 2000; 361(2):520-526.

4. Romeo N, Bosio A, Tedeschi R, Caneveri V. Growth of polycrystalline $\mathrm{CdS}$ and CdTe thin layers for high efficiency thin film solar cells. Thin Solid Films. 2000; 361(2):327-239.

5. Chung G, Park S, Cho K, Ahn B. Electrical properties of CdTe films prepared by close-spaced sublimation with screen-printed source layers. Journal of Applied Physics. 1995; 78(9):5493-5498.

6. Pinheiro W. Produção e Caracterização de Filmes Finos de CdTe Por Sublimação em Espaço Reduzido. [Unpublished Master Thesis]. Rio de Janeiro: Instituto Militar de Engenharia; 2004.

7. Anthony T, Fahrenbruch A, Bube R. Fundamentals of solar cells. Journal of Vacuum Science and Technology A. 1984; 2(3):1296-1302.

8. ASTM E112-88. Standard Test Methods for Determining Average Grain Size $; 1988$.

9. Dhere R, Al-Jassim M, Yan Y, Jones K, Moutinho H, Gessert T, Sheldon $\mathrm{P}$, Kazmerski L. CdS/CdTe interface analysis by transmission electron microscopy. Journal of Vacuum Science and Technology A. 2000; 18(4):1604-1608.

10. Zelaya O, Sánchez-Sinencio F, Mendoza-Alvares J. Large grain size CdTe films grown on glass substrates. Journal of Applied Physics. 1988; 63(2):410-413.

11. Moutinho H, Dhere, R, Levi D, Al-Jassim M, Kazmerski L. Investigation of induced recrystallization and stress in close spaced sublimation and radio-frequency magnetron sputtered CdTe thin films. Journal of Vacuum Science and Technology A. 1999; 17(4):1793-1798. 